\title{
Problems Faced by Doctors while Managing COVID Patient in Institutional Isolation Duty during COVID-19: An Article
}

\author{
Meenal Rajput ${ }^{1}$, Dr. Sourya Acharya ${ }^{2}$ \\ ${ }^{1}$ Intern, Dept. of Community Medicine, Jawaharlal Nehru Medical College, Datta Meghe Institute of Medical \\ Sciences (Deemed to be University), Sawangi (Meghe), Wardha-442001, Maharashtra, India, \\ ${ }^{2}$ HOD \& Professor, Dept. of Medicine, Jawaharlal Nehru Medical College, Datta Meghe Institute of Medical \\ Sciences (Deemed to be University), Sawangi (Meghe), Wardha-442001, Maharashtra, India, \\ emails:12drminals10@gmail.com, ${ }^{2}$ souryaacharya74@gmail.com
}

Type of Article: Original Article

Conflict of Interest: none

Funding: Non Funded

\begin{abstract}
Background

Once again the globe is facing the menace of a lethal virus. After the Ebola crisis in Africa, the WHO declared the novel coronavirus to be a pandemic, started spreading from Wuhan city in China in December 2019. We need to acknowledge and appreciate the efforts of doctors in this covid19 crisis for performing their duties without even thinking of being infected by the virus and risking their life. Doctors are at the forefront in the war against the COVID-19 pandemic, they are facing many obstacles in performing their duties.. Doctors are going through many difficulties in isolation duty. Physicians have been called upon to work under radically new situations, to feel exhausted due to heavy workloads and protective equipment, to fear of being exposed and infecting others, to feel helpless in coping with patients' conditions, and to navigate a stressful situation. These all were the main, which is to be manipulated and controlled by the health worker providers.
\end{abstract}

\section{Objectives}

This article is to find out the issues faced by the doctors while working in the isolation duty.

Result

Study among 50 doctors, $98 \%$ of them has received training in donning and doffing of PPE, $88 \%$ experience shortage of amenities in isolation wards, while $52 \%$ face interruption while doing work in PPE. $100 \%$ of them experience suffocation while wearing PPE. $12 \%$ of them have a fear of being isolated while working in isolation wards. $16 \%$ of them were worried and tensed all the time while working in covid ward.

\section{Conclusion}

It is required to identify the difficulties that are faced by the doctors while working in covid isolation duty and at most to resolve them so that they can work comfortably and to strengthen the protection of those persons who carry out their duties fearlessly.

Keywords

Covid19, Pandemic, Isolation duty, Donning and Doffing, Amenities.

\section{INTRODUCTION}

Coronavirus is caused by virus SARS COV2 i.e., Severe Acute Respiratory Coronavirus 2. It is genetically similar to SARS Coronavirus breakout in 2002. In humans it ranges from common cold to MERS, SERS. $1^{\text {st }}$ case of coronavirus contracted in Wuhan city, Hubei, China on $1^{\text {st }}$ December 2019. On January $30^{\text {th }} 2020$ $1^{\text {st }}$ case of Novel Coronavirus was reported in India. They are large and enveloped RNA virus with helical symmetry. It is carrying crown like peplomer spikes giving appearance of solar corona. Its RNA is linear with positive sense double stranded RNA. It is transmitted through respiratory droplets from infected person's cough, sneeze or while talking. This can also be transmitted by touching a contaminated surface.

Doctors are the forefront rejoinder in each country during the covid19 pandemic. The gratification of becoming a trained physician and the virtuous responsibility to 
accept care of COVID patients cannot be burdened by unnecessary risks. It entails an immense risk for clinicians as it can be acquired even though the disease progresses asymptomatically in certain patients.

"The unpredictability of clinical picture and the complexity of spread, along with an increase in morbidity and mortality, are potential causes that are bothering the frontline physicians in the on-going pandemic. Concerns vary from fear of infection, insufficient personal protective equipment (PPEs) and a sense of inadequate help at work, and anxiety about the spread of infection to colleagues and family members. Furthermore, at the individual basis, the Health professional may have questions about blame and prejudice on the part of colleagues, acquaintances and community. Food and transport have also been a significant obstacle due to the shutdown. This will contribute indirectly to tension, anxiety, trepidation at work, anger, problems of adaptation, and psychological fear."[1].

"Analyse the findings responsible for reducing the stress induced by COVID-19 (Cai et al., 2020). Relative's protection has played a crucial role in alleviating stress, along with corrective advice, effective disease prevention strategies and positive thinking on the part of their colleagues. (More on female staff). Kang et al. (2020) concluded that the degree of contact with recorded or suspected cases and access to therapeutic materials/resources is connected to the extent of mental health issues."[2].

As the cases in the fever clinic, respiratory opds and infectious opds increased, the number of reported and confirmed cases was burdened in hospitals, resulting in a rapid modification of general wards to the isolation wards, and the unexpertised health care provider, such as interns, technicians and para-clinical staff, stepped in to provide care and duty to the patient with covid19.
These stresses can be minimised if a healthy environment is assured with wellequipped protection devices such as PPEs. Maintaining everyday life, persistent relations with others, friends and family, and admiring society are few strategies to overcome stress. The purpose of the study is therefore to identify the problems faced by doctors when treating covid-positive patients in institutional isolation during the Covid19 pandemic.

This is the offline survey which is related to problems faced by the doctors who were managing covid patients in covid isolation wards and icus. In this, total 50 doctors are question and based upon their experience, this study is done.

\section{METHOD AND MATERIAL}

\section{Objective:}

To assess the challenges faced by doctors working in covid isolation duty.

\section{Study and Material:}

We did a retrospective study using an offline survey. The survey is conducted by paper survey i.e. traditional paper and pencil survey with one on one interview. The study includes doctors from various departments, who were working in covid19 duty. Most of the participants were joined through snowball sampling.

\section{Data collection:}

This is a paper-pen based survey and is conducted by the personal interviews. Study includes 50 doctors which includes junior and senior residents. After taking consent from all, questionnaire are given and based upon their experience their answers have been noted down. Question included the age group, problem faced by doctors in isolation duty regarding were collected and assessed. According to it the article is made.

\section{DISCUSSION}

According to the study, the challenges that came across by the doctors in isolation duty were due to: "Lack of strategic planning in the field of health and social 
care due to lack of disease outbreak surveillance and management techniques and protocols, as it induced chaos and anxiety among health care professionals as they could not anticipate the scale of the COVID-19 pandemic. It also led to a feeling of uncertainty, leading to low performance and cooperation in the workplace."

"In these conditions, health providers are now being extremely significant points of reference for people in terms of information about how to deal with the health crisis. This can make them feel entirely responsible for handling the situation and often impair their ability to understand their own human emotions, interests and concerns."[3]

PPE is one of the most crucial parts for the battle against an infective outbreak such as COVID-19. Almost all study participants mentioned a glaring lack of PPE in their hospitals. This exposed the health professionals to possible infection of COVID-19. There is no question that the lack of PPE brought fear and anxiety among doctors and nurses who work in the Covid19 isolation departments and the Icus. In consideration of this, it is essential for all health and social services organisations to have a clear policy on the procurement of personal protective equipment. This will maintain a good supply of PPE and security for all concerned.

"Social distance is key in the prevention of infection among the population. It is highly important to avoid infections in enclosed areas such as buildings and workplaces. Almost all participants, reported difficulties with respect to the enforcement of social distances between the individuals they care for."[4]

Such problems were common to individuals with serious disabling conditions. It is also necessary to increase the staff-to-individual ratio during a pandemic to ensure that individuals are helped to maintain social distances and avoid cross-infections.

"It feels clumsy to walk and practise things. Even though I'm good at venepuncture, I can't have the experience that blood vessels can take blood with three layers of gloves, even though I palpate carefully. My glasses and my safety goggles get blurred when I'm damp, and it's really hard to do things like getting progress reports, taking samples and administering medicines. I've got to keep the medication close on my face mask to read the words on it. I'm very frustrated and grumpy, as I have so much stuff to do, but I can't see it all clearly."[5]

"In these conditions, health providers are now being extremely significant points of reference for people in terms of information about how to deal with the health crisis. This can make them feel entirely responsible for handling the situation and often impair their ability to understand their own human emotions, interests and concerns."'[6]

"Both health staff, physicians, nurses are exhausted (Jakovljevic 2020) for several reasons: long working hours, immense strain, including high risk of illness, lack of protective equipment, anger, sexism, isolation, physical weakness and family alienation and exhaustion. Kang et al. (2020) stresses that hospital operating environments can induce psychiatric disorders such as stress, anxiety, depressive symptoms, insomnia, denial, frustration, and terror. Xiao et al. 2020. 2020. Reports that medical workers treating patients with COVID-19 showed anxiety associated with stress and decreased sleep quality.’[7]

\section{Sociodemographic data:}

Study includes 50 doctors, all are directly involved in treating the covid19 positive patient and it includes junior residents and senior residents of all the departments. Among which 14 are females and 36 are males. The partakers were age group of 25-35 years. 
At this time doctors are at utmost risk of getting infection but then also without thinking about anything they do their job honestly, too. Beside these doctors were facing so many difficulties while working in wards and icus due to many reasons.

"As pandemic hit the country many hospitals and institution gave training regarding the infectious control and the basic safety measures and also received training in donning and doffing. Figure 1: In this study it is seen that $6 \%$ of them have received training and $94 \%$ of them have gained self-knowledge in infectious control. Most of them have received training in donning and doffing i.e. around $98 \%$ of them."

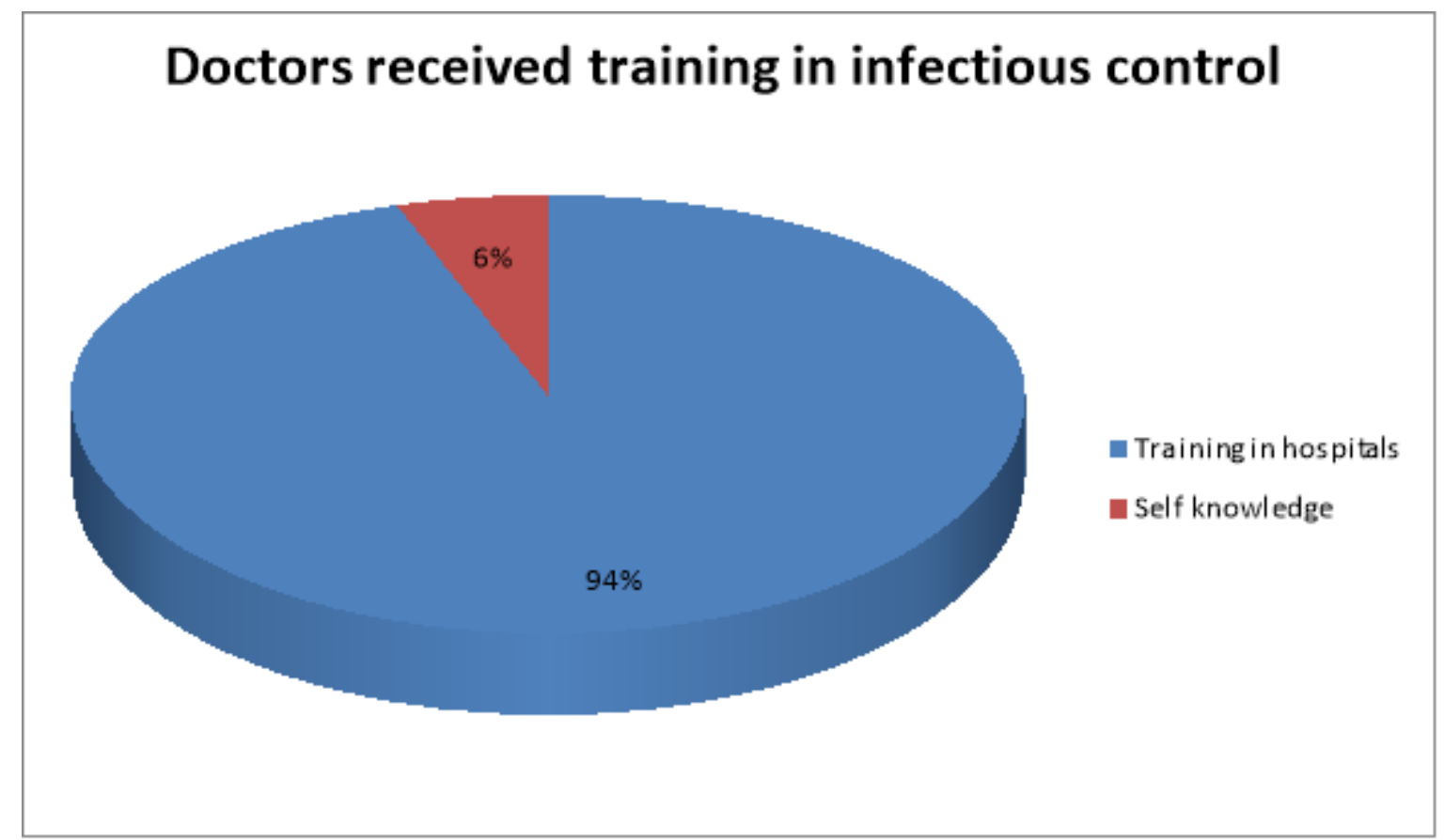

Figure1: Doctors received training in infectious control

Figure 2:Doctors got training in donning and doffing of ppe, prior posted in covid duty. 


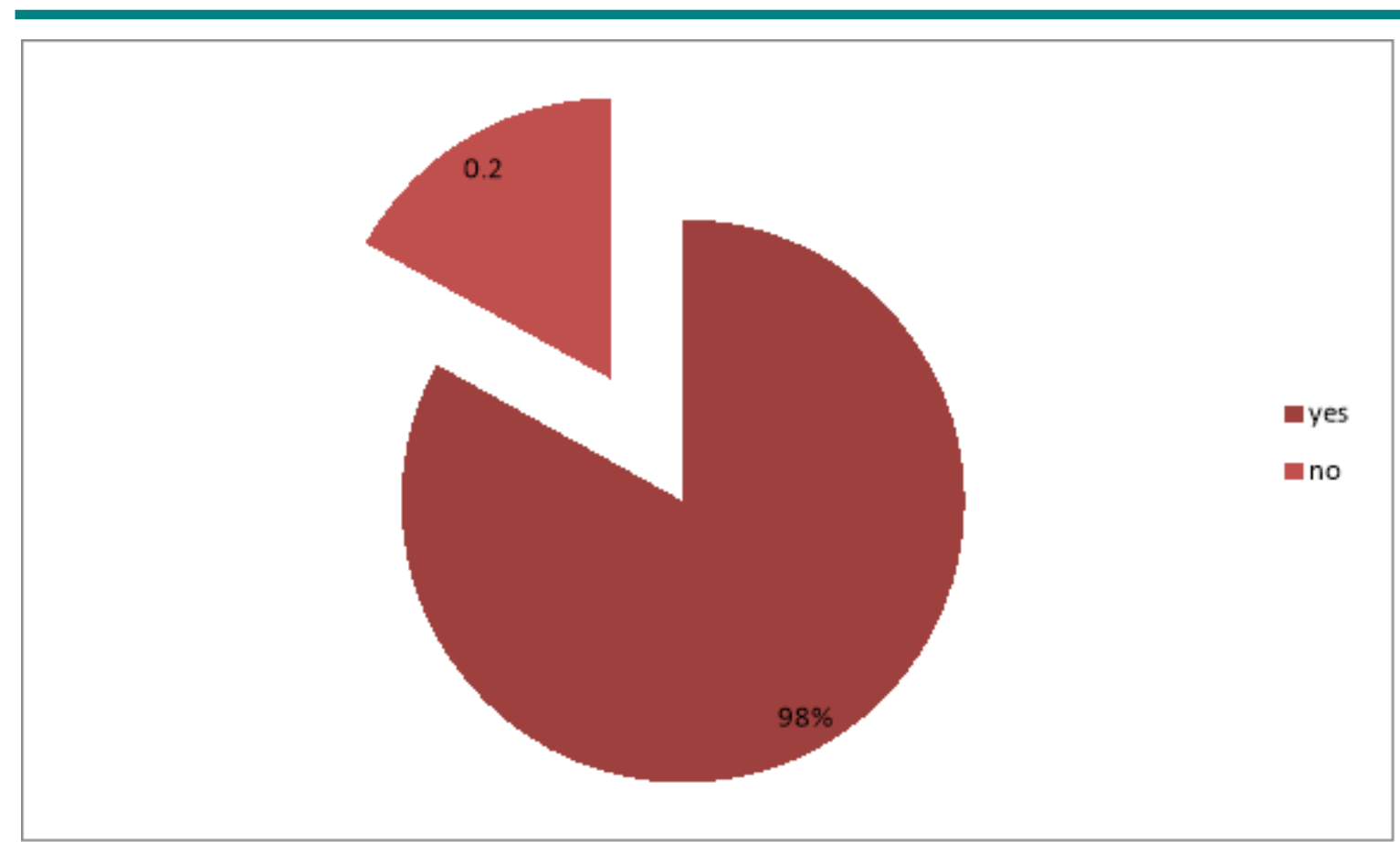

Figure 2 Doctors received training in donning and doffing of PPE.

As the cases are increasing day by day the need for the doctors is also increasing. In order to cope up with this situation working hours of the doctors has been increased so, the working hours in the wards are as follows,

When $\mathbf{5 8 \%}$ are working 8-12 hours and when $\mathbf{4 2 \%}$ are working 5-8 hours a day. While working in isolation, doctors have to wear PPE so as to protect themselves from acquiring infection. Doctors face many difficulties while wearing PPE as it interrupts while doing work. As it includes problems related to PPE while doing work, PPE related skin issues.

\section{PROBLEMS FACED BY DOCTORS DUE TO PPE:}

"The types of protection needed to tackle a particular mode of transmission include:-

(1) gloves and aprons as contact measures,

(2) gloves, aprons, fluid-resistant surgical masks with eye protection (goggles or visors) for

Droplet transmission and,

(3) gloves, fluid-repellent long-sleeved gloves, eye protection, and filtering face mask $2 / 3$
(FFP2/3) or N95 breather during aerospace."[8]

There were so many issue that doctors were facing while wearing PPE and working in isolation duty. Like interruption while doing work due to PPE are uncomfortable, difficulty in breathing, feel like exhausted in long working hours. They even find difficulty in identifying things due to glare and fog in PPE face shield. This can also occur in individual those, who are wearing vision spectacles. Another problem is decreased tactile sensation i.e. reduced sensation and all these leads to create problems in palpating veins, taking samples, putting i.v. catheters. Figure 3: In the analysis it seen that almost all i.e. $100 \%$ were sweating the entire long in ppe as soon as they wear. $64 \%$ experiences hunger and urinating difficulty, as once we wear ppe can only remove it after completing the duty. 58\% (difficulty in sensing things), $70 \%$ feels (difficulty in perceiving things), $84 \%$ experiences difficulty in communication. $82 \%$ felt heaviness and uncomfortable in ppe and all participants have experienced suffocation. 


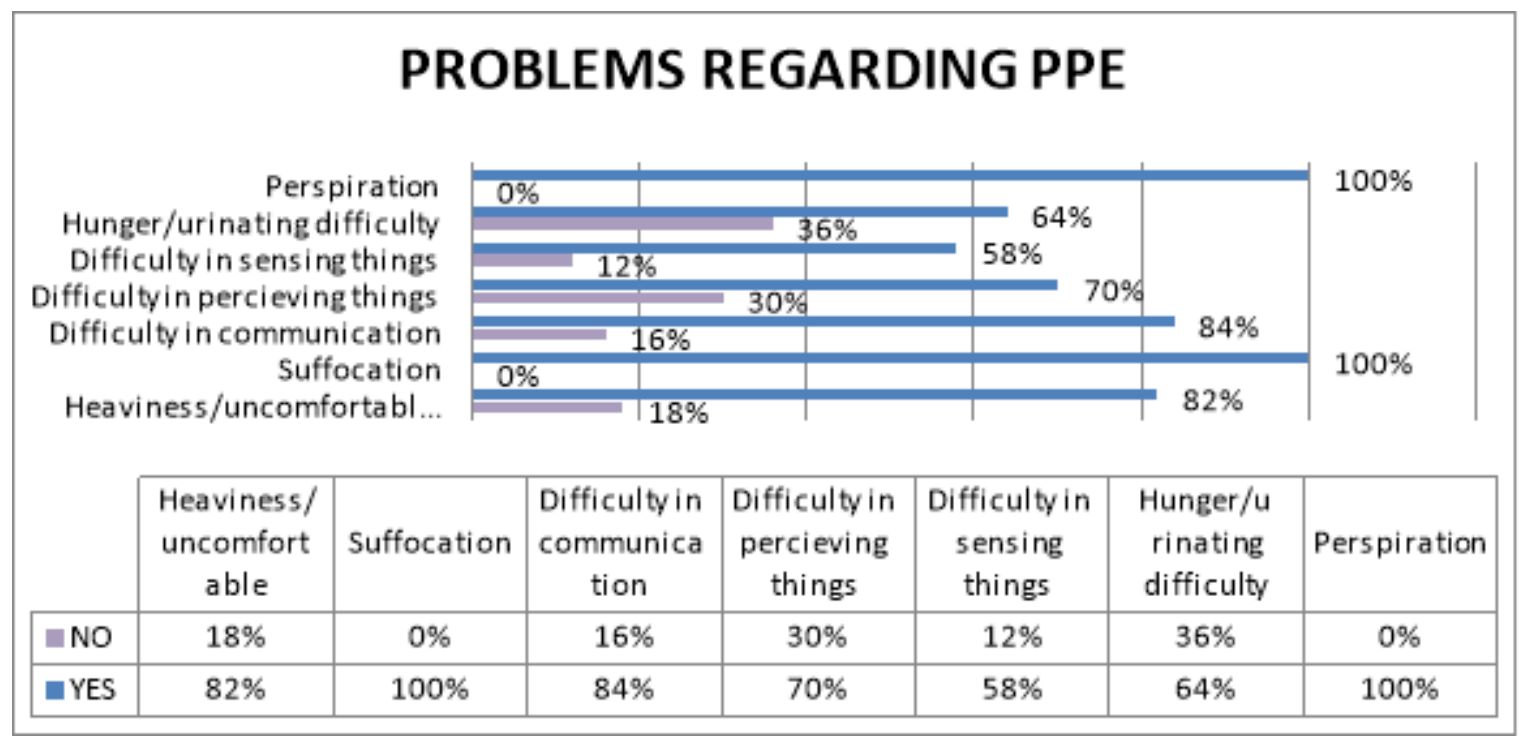

Figure 3 Challenges faced by doctors while wearing PPE.

\section{SKIN RELATED ISSUES WHILE WEARING PPE:}

As we all know the importance of the PPE kit i.e.it includes layers of masks, gloves, hooded caps, face shields, goggles, gowns and shoe covers for long hours makes them drained, uncomfortable and more over cases PPE related problems like rash, itching and injuries. As sweats accumulates and irritates the skin leads to redness, rash and itching. In study it is noted that $40 \%$ of them have got rash, $54 \%$ experiences itching and $16 \%$ got the injuries related to PPE.

Figure 4: The injuries associated with ppe are device related injury(58\%), moist associated injury due to perspiration(38\%), skin tear injury(4\%) and among them 58\% have no complain of injury related to ppe. The most commonly mentioned dermatosis was irritant contact dermatitis (ICD; 39.5 per cent followed by friction dermatitis (25.5 percent ). Goggles was perhaps the most common delinquent agent among all the PPEs that triggered certain dermatosis (51.92 per cent), followed by N95 masks (30.77 per cent) and face shields (17.31 percent ). (17.31 percent). (17.31 percent ). (17.31 percent ). Nasal bridge (63 per cent) was the most common anatomical site affected by dermatosis followed by cheeks and chin (26 percent ). There was however a substantial overlap between various dermatosis with multiple site affliction.[4] 


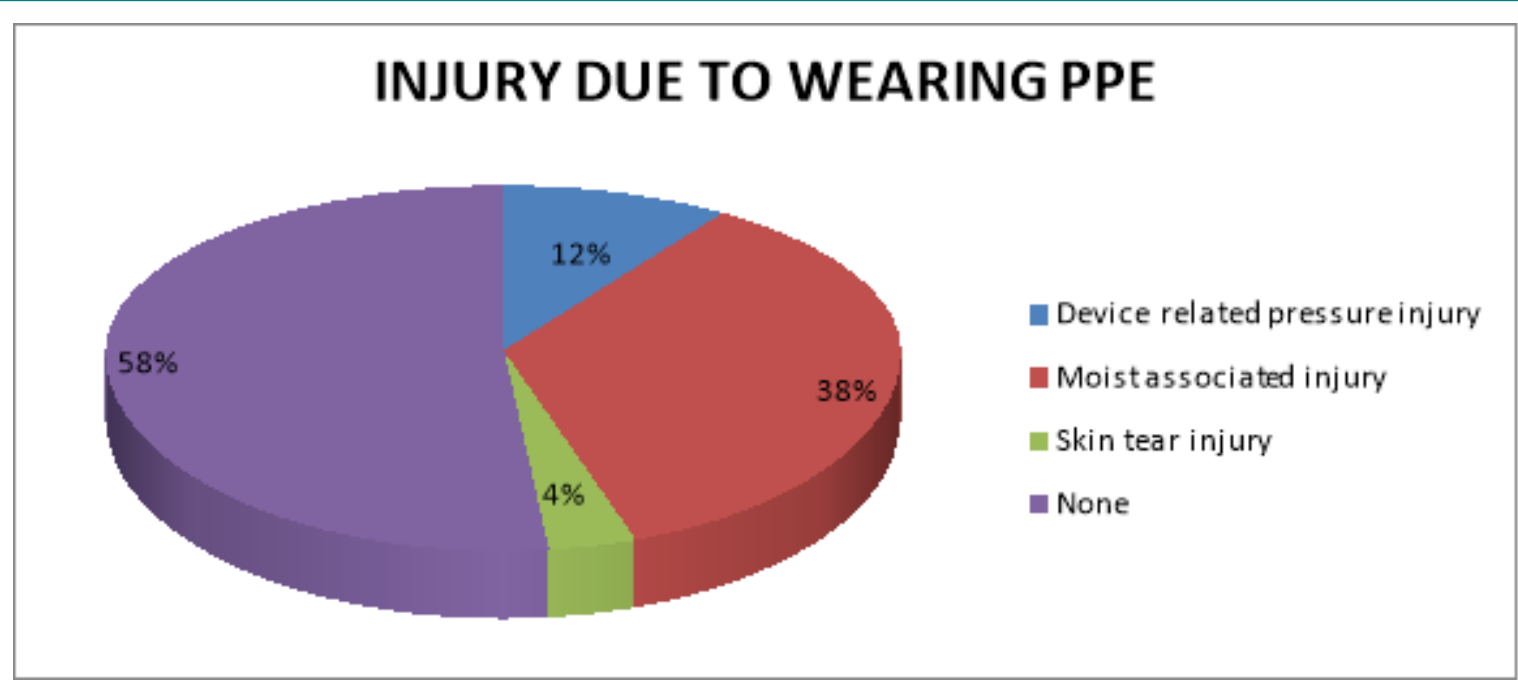

Figure 4: Injury related to PPE.

3. PROBLEMS FACED BY THE DOCTORS IN HOSPITAL:

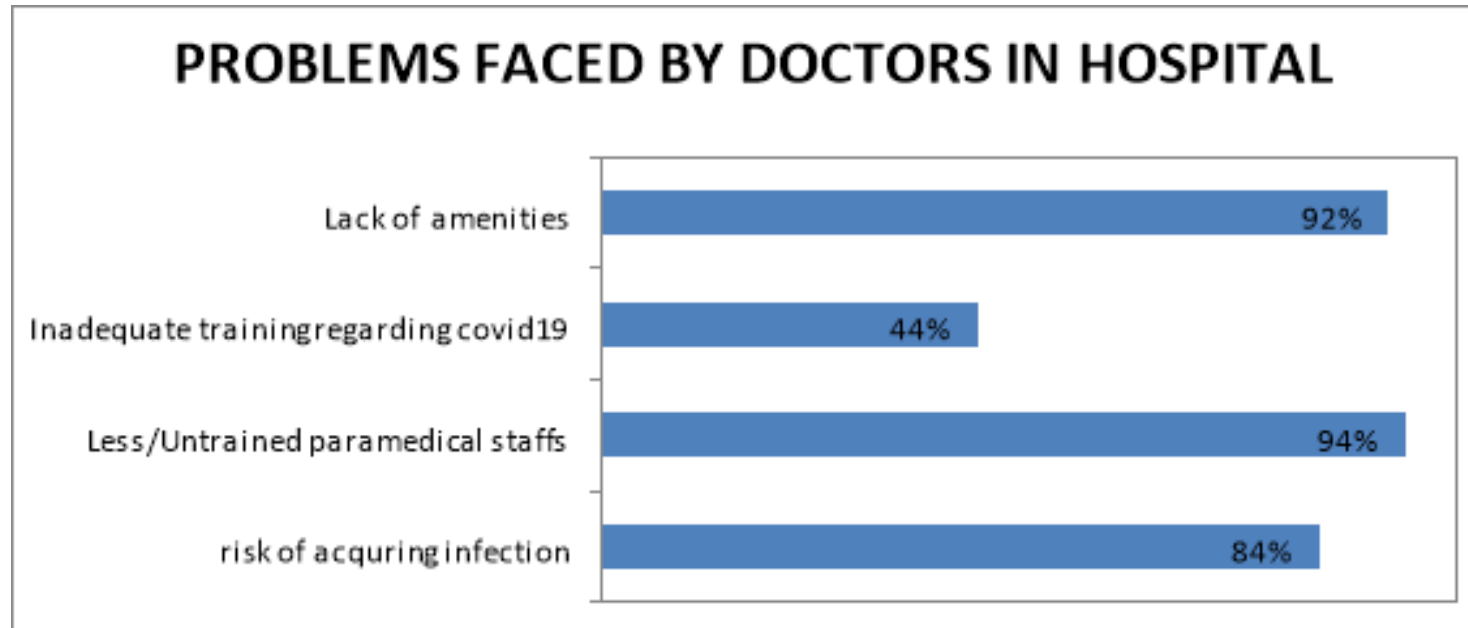

As the time is passing, cases are increasing and difficulties are also increasing. 92\% doctors have experienced lack of amenities workload and also staff decreased due to such as gloves, mask, face shield, good quality PPE. Their also been increased

infection and among them $84 \%$ have fear

Figure 5: Problems faced by doctors in hospital setting

quarantine after isolation duty and acquiring infection while working in covid duty. Figure 5: It is also seen that doctors in isolation duty have experienced, less or untrained paramedical staffs i.e. (94\%) as they do not have much experience about the treatment protocol and about the medications and management of covid19 positive patient. Doctors they too fear of acquiring infection are $84 \%$.

4. PROBLEMS THAT DOCTORS FACED AT PERSONAL LEVEL:

Figure 6: Doctors, managing and treating covid positive patients have fear of getting of being isolated by the society. $8 \%$ of them have family pressure not to work in isolation wards. Instead of all these they are working, even by knowing this that their family and friends are at high risk because of them (78\%). Other problems includes emotional breakdown, disturbed daily activity.

"While physicians perceived that there was less risk of COVID-19 being contracted out of work, when they returned home from work, they were still concerned about infecting their family members. The proportion of participants (72 per cent) 
stated taking precautions at home to keep their families safe; the most widely cited precaution was to exclude the rest of the family (45 per cent); other examples were to remove and wash their clothes when they arrived at home and to wear a surgical mask, not to share utensils and keep physical distance from family members.."[9]

"The risk of individual health from coronavirus is quite worrying, but the chance of infecting their families due to exposure at work is irrational and unreasonable. The HCW was also faced with a kind of 'persecution' of culture. Several HCWs were ordered to leave their rental housing on the belief that they might carry this disease from their workplace (hospitals) to society.”[10]
"Recognizing the challenging and highly valuable work performed by physicians at the advent of the COVID-19 infection is an important part of society's response. However, we should try to get there without using a language of compassion that encourages self-sacrifice ideas but does not completely represent the importance of reciprocity, or that there are limits on the amount of personal danger that healthcare workers should expect to bear. Although the concept of self-courage is compelling, it can also have detrimental psychological consequences for healthcare professionals too."[11] 


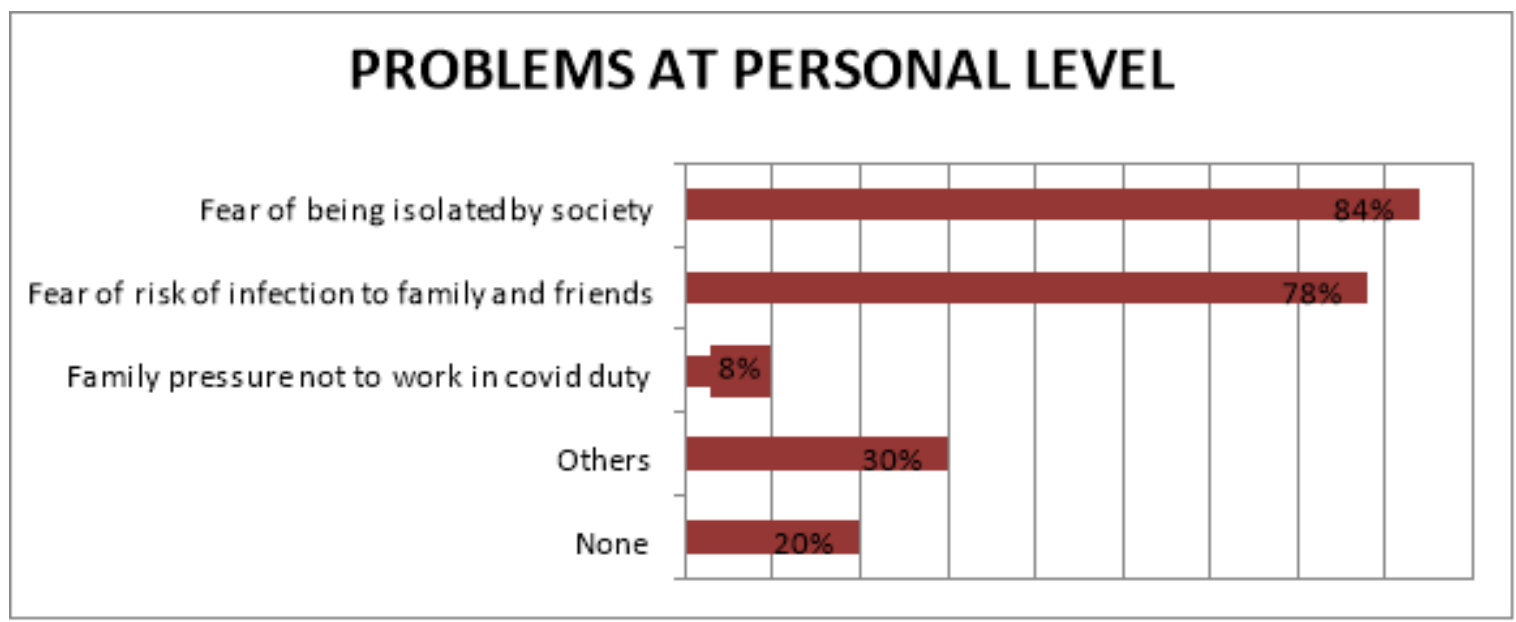

Figure 6: PROBLEMS FACED BY DOCTORS AT PERSONAL LEVEL

5. MENTAL HEALTH AMONG DOCTORS IN COVID WARD:

PSYCOLOGICAL ISSUE FACED BY DOCTORS IN COVID DUTY

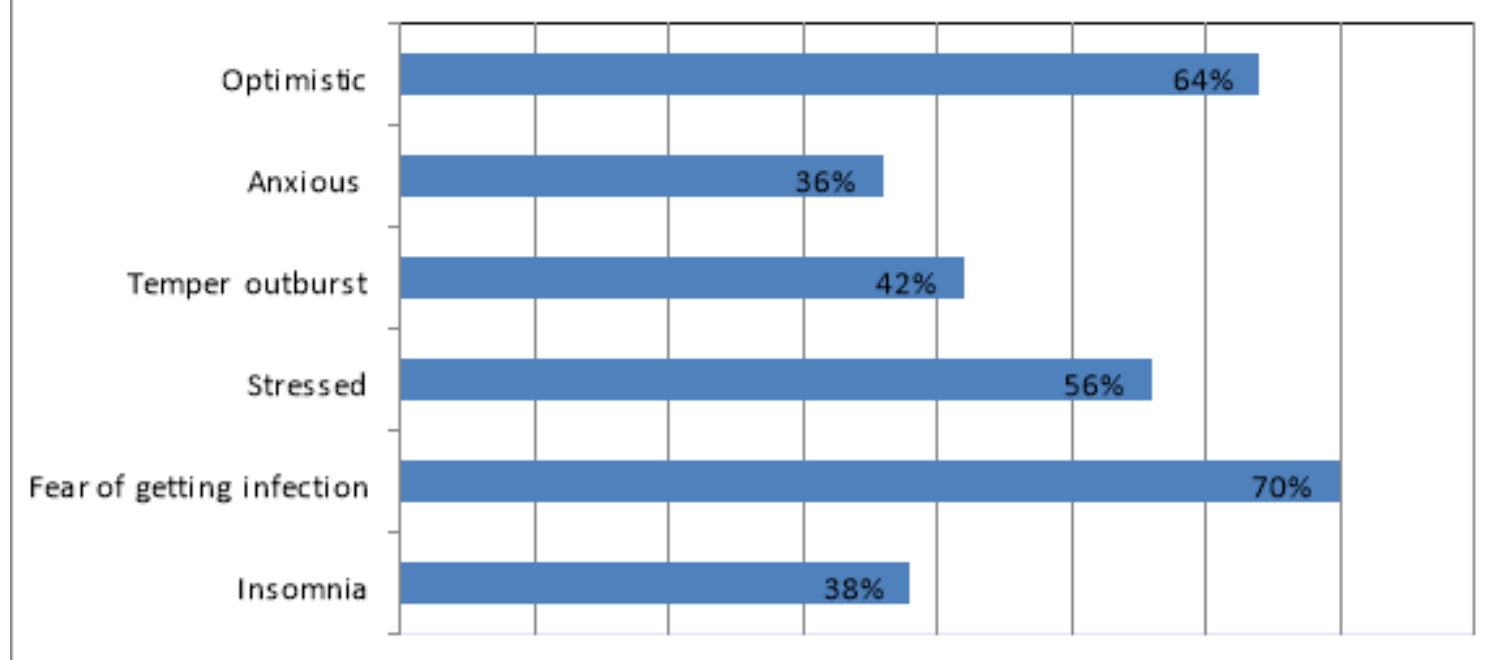

Figure 7: PSYCHOLOGICAL ISSUES FACED BY DOCTORS IN COVID DUTY

Figure 7:It is to assess the psychological problems like stress, anxiety, depression and tension among the doctors working in covid19 isolation wards. Study states that among 50 doctors, most of them were optimistic, about $36 \%$ were anxious and $56 \%$ of them were stressed.

$70 \%$ of them have fear of getting infection and $82 \%$ of them are going through mental stress. It seems that there were some possible cause of emotional stress and that are change in environment, disease related issues, acquiring infection, increased work load and health of family and self. It is seems that $42 \%$ have experienced temper outburst. $38 \%$ of them have also experience insomnia.

"Front-line service staff have a vital role to play in delivering services to infected patients. Working in such an extraordinary environment, typically outside their capability and at risk of illness, presents an 
elevated risk of mental health issues for HCWs. Literature shows that there is a high incidence of mental health issues in front-line workers (such as burnout, insomnia, nausea, depression, anxiety, PTSD, and so on) induced by multiple bio psychosocial causes."[12]

"The effect of Covid-19 on the mental health of health worker is more in those who work personally with the patients infected by the infection. 50.4 per cent of health staff had depression, 44.6 per cent had anxiety, and 34 per cent had trouble sleeping."[13]

Strong practise has drained health-care workers both physically and mentally. Health-care professionals have demonstrated their power and the pneuma of professional commitment to overcome the struggle. Enormous care should be provided to protect the well-being of health care providers.

To cope up with the difficulties that are faced by the doctors, can be reduced by the many ways and also by implementing some simple steps that decreases their concern regarding their physical and mental health. Like by providing them a safe environment and regular thermal screening and tests can minimize the risk of infection in doctors.

"Regular support activities (such as peer support programmes) accessible to health professionals should include a briefing on moral injuries, knowledge of other causes of mental illness and what to look for. Also the most resilient members of the team can be overcome by circumstances of personal importance, such as offering treatment to someone who is of personal interest.It reminds them of a family or a friend.”[14]

They can provide them good quality PPE which makes the doctors to breathe comfortably, proper fitting mask made up of good material. Adequate breaks and frequent rotation of duties can decrease the stress and workload.
For psychological wellbeing, they should be counselled regularly and proper measures should be taken to tackle the mental issue. Other recreational facilities should be there for them like music, TV, exercise and meditation. They should be appreciated by their seniors and colleagues for booting their will and mood.

"Certainties and concerns associated with the spread of the virus, along with mass lockdowns and economic decline, are expected to lead to increased suicide and suicide-related mental disorders."

"The goal is now to identify effective ways and means to develop and expand public health awareness and practise. This is important not only for educating the population on the importance of disease prevention, hand hygiene in the prevention of communicable diseases prevalent in India, but also on the importance of various health workers in the implementation of health programmes.'[15]. Some of the related studies on Covid 19 and healthcare issues were reported[16-20].

\section{Conclusion:}

"This comprehensive evaluation analysed the psychological state of physicians serving in isolation during the COVID-19 pandemic and highlighted the associated risk factors. Rising incidence of adverse psychiatric symptoms has been documented in most studies.

The COVID-19 pandemic poses an unparalleled danger to the mental health of healthcare personnel. In addition to flattening the viral propagation curve, priority needs to be given to the prevention of psychological illnesses such as anxiety, depression, etc.); In this study it is seen that doctors were facing so many difficulties during this pandemic while managing covid patient in isolation wards. So these issues can be handled and tackled by implementing proper measures and taking right steps. A robust plan and direction system under good leadership is the need for an hour to solve these hardships and provide HCPs with a stable 
and secure atmosphere where they can function without compromise.

\section{References:}

1. Rathore P, Kumar S, Choudhary N, Sarma R, Singh N, Haokip N, Bhopale S, Pandit A, Ratre BK, Bhatnagar S. Concerns of healthcare professionals managing COVID patients under institutional isolation during COVID-19 Pandemic in India: A descriptive cross-sectional study. Indian Journal of Palliative Care. 2020 Jun 1; 26(5):90.

2. Spoorthy MS, Pratapa SK, Mahant S. Mental health problems faced by healthcare workers due to the COVID-19 pandemic-A review. Asian journal of psychiatry. 2020 Jun 1; 51:102119.

3. Singh M, Pawar M, Bothra A, Maheshwari A, Dubey V, Tiwari A, Kelati A. Personal protective equipment induced facial dermatoses in healthcare workers managing COVID-19 cases. Journal of the European Academy of Dermatology and Venereology. 2020 May 12.

4. Liu Q, Luo D, Haase JE, Guo Q, Wang XQ, Liu S, Xia L, Liu Z, Yang J, Yang BX. The experiences of health-care providers during the COVID-19 crisis in China: a qualitative study. The Lancet Global Health. 2020 Apr 29.

5. McConnell D. Balancing the duty to treat with the duty to family in the context of the COVID-19 pandemic. Journal of Medical Ethics. 2020 Jun 1;46(6):360-3.

6. Salopek-Žiha D, Hlavati M, Gvozdanović Z, Gašić M, Placento H, Jakić H, Klapan D, Šimić H. Differences in distress and coping with the COVID-19 stressor in nurses and physicians. Psychiatria
Danubina. 2020 Aug 13;32(2):28793.

7. Ahmed J, Malik F, Arif TB, Majid Z, Chaudhary MA, Ahmad J, Malik M, Khan TM, Khalid M. Availability of personal protective equipment (PPE) among US and Pakistani doctors in COVID-19 pandemic. Cureus. 2020 Jun;12(6).

8. Savoia E, Argentini G, Gori D, Neri E, Piltch-Loeb R, Fantini MP. Factors associated with access and use of PPE during COVID-19: A cross-sectional study of Italian physicians. Plos one. 2020 Oct 12;15(10): $\mathrm{e} 0239024$.

9. Health Care Workers Are Facing Several Challenges During COVID-19 Pandemic: Dr. (Prof. Raju Vaishya) [Internet]. The India Times. 1970 [cited 2020 Sep 4]. Available from: https://timesofindia.indiatimes.com /readersblog/newspost/health-careworkers-are-facing-severalchallenges-during-covid-19pandemic-dr-prof-raju-vaishya$\underline{11529 /}$

10. Cox CL. 'Healthcare Heroes': problems with media focus on heroism from healthcare workers during the COVID-19 pandemic. Journal of medical ethics. 2020 Aug 1;46(8):510-3

11. Gupta S, Sahoo S. Pandemic and mental health of the front-line healthcare workers: a review and implications in the Indian context amidst COVID-19. General Psychiatry. 2020 Oct;33(5).

12. Thapa B, Gita S, Chatterjee K, Devrani A. Impact of COVID-19 on the Mental Health of the Society \& HCW (Healthcare workers): A Systematic.

13. Greenberg N, Docherty M, Gnanapragasam S, Wessely S. Managing mental health challenges faced by healthcare workers during covid-19 pandemic. bmj. 2020 Mar 
26;368.

14. Barello S, Palamenghi L, Graffigna G. Empathic communication as a "Risky Strength" for Health during the COVID-19 pandemic: the case of frontline italian healthcare workers. Patient Education and Counseling. 2020 Oct 1.

15. Iyengar KP, Jain VK, Vaishya R. Current situation with doctors and healthcare workers during COVID19 pandemic in India. Postgraduate Medical Journal. 2020 Aug 18.

16. Agrawal, D., N. Khara, B. Mundada, N. Bhola, and R. Borle. "COVID-19 and Its Financial Effects on the Dental Fraternity and Health-Care Workers: A Literature Review." International Journal of Research in Pharmaceutical Sciences 11, no. Special Issue 1 (2020): 628-31. https://doi.org/10.26452/ijrps.v11iS PL1.2883.

17. Jameel, P.Z., and A.M. Taksande. "COVID-19: A Review of Drugs and Therapies for Children." Sri Lanka Journal of Child Health 49, no. 3 (2020): 210-17. https://doi.org/10.4038/sljch.v49i3. 9136.

18. Mujbaile, N.S., and S. Damke. "The Impact of COVID 19 on Pregnant Women and Child Health." International Journal of Research in Pharmaceutical Sciences 11, no. Special Issue 1 (2020): 1367-73. https://doi.org/10.26452/ijrps.v11iS PL1.3645.

19. Sharma, D. "Preventive Measures for COVID-19 Health Care Professionals." International Journal of Research in Pharmaceutical Sciences 11, no. Special Issue 1 (2020): 1307-12. https://doi.org/10.26452/ijrps.v11iS PL1.3626.

20. Madhu, P.P., Y. Patil, A.R. Shinde, S. Kumar, and P. Phansopkar. "The
Great Awakening-Digitalization in Dental Healthcare during the Pandemic Covid19." International Journal of Research in Pharmaceutical Sciences 11, no. Special Issue 1 (2020): 380-84. https://doi.org/10.26452/ijrps.v11iS PL1.2730. 